\title{
Effect of Spacer and Alkyl Chain Groups of the Synthesized Cationic Gemini Surfactants on the Surface Modification of Nano Na-Montmorillonite and its Dye Adsorption from Textile Waste Water
}

\author{
AJavad Ahmadishoar ${ }^{1}$, S. Hajir Bahrami ${ }^{*}$, Brahman Movassagh ${ }^{2}$, S. Hossain Amirshahi ${ }^{1}$ and \\ Mokhtar Arami ${ }^{1}$ \\ 'Textile Engineering Department, Amirkabir University of Technology,Tehran, Iran; hajirb@aut.ac.ir \\ ${ }^{2}$ Chemistry Department, K.N. Toosi University of Technology, Tehran, Iran
}

\begin{abstract}
Cationic surfactants as new modifiers for clays affect the clay interlayer structure. In this paper the effect of chain length of gemini surfactants on the interlayer changes of Na-montmorilinite and its dye adsorption from waste water has been reported. Several novel quaternary ammonium cationic gemini surfactants having vaious alkyl chain and spacer lengths were synthesized according to reaction of tertiary amine with corresponded alkyl halide. Subsequently organoclays were prepared by intercalation of synthesized gemini cationic surfactants $(2-6-2,2-10-2,4-6-4,4-10-4$ and 10-6-10 and conventional cationic surfactants (mono)) onto Na-montmorillonite (MMT-Na+) via ion exchange reaction. The structures of the synthesized surfactants were analysed using 1H NMR, 13C NMR and FT-IR spectroscopy techniques. The modified montmorillonite was also characterized by FT-IR spectroscopy of attenuated total reflection (ATR) and X-ray diffraction techniques (XRD). The results show that gemini surfactants have better intercalation than conventional ones. The basal spacing of modified montmorillonite increase with incorporation of gemini surfactants having longer spacer length and chains length. However, gemini surfactant, 4-10-4 and 10-6-10 were more effective in this regards. Dye adsorption experiments show that by surface modification, the adsorption capacity of acid dye improves and MMT-Na+ modified with gemini surfactants show higher dye adsorption capacity compared to the montmorillonite modified with conventional one (Mono) and as the alkyl chain and spacer length of the surfactants increase, this property increases. Our findings show that these kind of modifications on Na-montmorillonite can make it a promising absorbent for organic pollutants such as dye removal from waste water.
\end{abstract}

Keywords: Adsorption, Gemini Surfactants, Montmorillonite, Nanoclay, NMR, Surface Modification,

\section{Introduction}

Clay minerals have found various applications both in academia and industry.These materials are low cost, high abundance in naturef, cation exchange capacity (CEC), high surface area and strong adsorption capacity? Montmorillonite (MMT) belongs to smectite group of clays and is composed of 2:1 type layered silicate with two tetrahedral silicates and one octahedral layer-e, The montmorillonite structure is made of an octahedral layer of aluminum which has been sandwiched between two tetrahedral layers of silica. Because of isomorphic substitution within the layers, the platelets have permanent net negative charge, which are compensated by the equivalent exchangeable cations such as $\mathrm{Na}^{+}$and $\mathrm{Ca}^{2+}$ in the interlayer. This clay with large specific surface area, high cation exchange capacity, expandability and swellability and other features has been a good choice of material for many applications ${ }^{\rho, 1}$. Sodium montmorillonite has higher swelling capacity in water compare to calcium montmorilloniten. The sodium montmorillonite is more common form of the five natural

* Author for correspondence 
varieties of smectite $e^{\text {p- }}$. However, Clay minerals specially the natural Na-montmorillonite are potential absorbents but their uptake capacities for carbon materials contaminants are quite low because of their high surface energy, hydrophilicity and narrow layer spacing]. For example raw montmorillonite shows low adsorption for some anionic pollutants because of the negative charges on the surface The main characteristic of sodium montmorillonite is its high ionic exchange capacity. In order to improve the potential of this clay by changing its affinity to organic contaminants and for better degree layers openning and distribution of the layers, it is advised to modify Na-montmorillonite by exchanging some species such as various surfactants with cations using ion exchange mechanism

Due to substitution of cations in the layers, there is a negative charge in the octahedral layer which can be compensated by some cations. In modification, cations in montmorillonite, such as $\mathrm{Na}^{+}, \mathrm{K}^{+}$and $\mathrm{Ca}^{2+}$, could be replaced by some chemical components. This may cause surface modification of the clays. These modifications increase the layers spacing; change the surface characteristics of clay from hydrophobic nature to hydrophilic and the adsorption capacity of the clay increase in $^{3}$. Choosing the organic material as the modifiers is an important factor in order to achieve effective organoclay. Different chemical components have been used for surface modification of nanoclay. Grafting of functional polymers to the surface of the clay, using ionic liquids such as imidozolium, pyridinium and phosphonium derivatives, 1, 6-diamino hexane and cationic surfactant are some of the reported modification types on nanoclay ${ }^{1-19}$. Some works have used anionic surfactants for modification of MMT20. The long carbonchain alkyl quaternary ammonium compounds (cationic surfactants) such as dodecyltrimethylammonium bromide (DTAB), cetyltrimethylammonium bromide (CTAB) and octadecyltrimethylammonium bromide $(\mathrm{OTAB})$ are classic materials for nanoclay modification. By cationic exchange mechanism, cationic surfactants are easily penetrated into the MMT interlayer and intercalation state can occour. Organoclays modified using cationic surfactants having longer hydrophobic chain show better performance in removing pollutants?

After such modification with cationic surfactants, organoclays have been used for different applications like adsorbent for organic materials, composite materials as reinforcing fillers, agents to controll the rheology offlouids, electric materials and as precursors in the production of mesoporous materials. All gemini surfactants posses at least two polar or ionic groups and two hydrophobic chains. These surfactants lower the surface tension of water and possess much lower critical micelle concentration (CMC) in comparison with corresponding single chain surfactants, ${ }^{2-27}$. The outstanding physico-chemical properties of these surfactants were the main reason for scientists to show great interest for investigating their applications as absorbant ${ }^{27-29}$. The hydrophobic chain group can vary in length. On the other side, the spacer can vary in length and chemical structure and also be varied hydrophilic or hydrophobic, rigid or flexible, short (e.g., an ethylene group) or long (12 methylene groups), and polar (polyether) or nonpolar (aliphatic, aromatic) $25,26,30$. The polar group present can be positive (ammonium), negative (sulphonate, phosphate, sulphate,), or nonionic (sugar, polyether). Nonsymmetrical and symmetrical gemini surfactants are well known. The polar groups of these surfactants may or may not be identical chains Gemini surfactants with more than two polar groups or chains are also available. This possibility can give infinite variations in the surfactant chemical structure compare to conventional surfactants ${ }^{2}$. However, there is little information available on gemini surfactants modified clay because of difficulties in preparation and purification only a few gemini surfactants of aliphatic quaternary ammonium salts are commercially available 3 . Some works reported the significant effect of the the amount of gemini surfactant and chain length on the arrangement of the intercalary surfactant ${ }^{\text {I. }}$. On the other hand spacer group of these surfactants largely influenced the physicochemical property of gemini surfactants. Many works have shown that the spacer type plays vital role in the aggregation of gemini surfactants. Zana et al. investigated on the effect of the alkyl chain length and spacer chain length (in gemini) on the CMC and micelle ionization degree in an aqueous solution?. In this paper, a series of cationic gemini surfactants with different carbon-chain alkyl group and different spacers have been synthesized. Five surfactants (gemini 2-6-2, 2-10-2, 4-6-4, 4-10-4 and 10-6-10 and commercially available cationic surfactants (mono)) were selected and the surface of the clay was modiffied with them in order to understand the influence of the chemical structure of cationic gemini on the surface modification of nanoclay. The structures of the synthesized surfactants 
were characterized by ${ }^{1} \mathrm{H}$ NMR, ${ }^{13} \mathrm{C}$ NMR and Fourier transform infrared spectroscopy (FT-IR). X-ray diffraction (XRD) and FT-IR was used to characterize the interlayer structure of intercalated alkylammonium silicates of organo-MMTs. These modified clays were used for adsorption of acid dye from textile wastewater.

\section{Materials and Methods}

\subsection{Materials}

Sodium Montmorillonite, MMT- $\mathrm{Na}^{+}$was used in this study as the clay, with trade name Cloisite- $\mathrm{Na}^{+}$with cation exchange capacity (CEC) of $92.6 \mathrm{meq} / 100 \mathrm{~g}$ clay (as reported by supplier) from Southern Clay Products Inc and used without any purification. Specific gravity of MMT- $\mathrm{Na}^{+}$was $2.86, \mathrm{pH}$ value of a $2 \%$ aqueous dispersion is 9 and $\mathrm{d}_{001}$ space is $11.7 \mathrm{~A}^{\circ}$.

$\mathrm{N}, \mathrm{N}, \mathrm{N}$, triethylamine, $\quad \mathrm{N}, \mathrm{N}, \mathrm{N}$, tributylamine, 1-bromohexane, 1-bromodecane, 1,6-dibromohexan, 1,10-dibromodecan and dry acetone were purchased from Merck and N,N,diethylamine, diethylether and dichloromethane were purchased from Loba Chemie company and all materials used without any purification. $\mathrm{N}, \mathrm{N}$,diethyldecylamine was synthesized according to Scheme 1.

An acid dye (Acid blue 92) was purchased from Sigma Aldrich and solution of dye with concentration of 200 $\mathrm{mg} / \mathrm{l}$ was prepared for dye adsorption studies.

\subsection{Synthesis}

\subsubsection{Synthesis of Amine}

(reaction of secondary amine with alkyl amine to obtain tertiary amine)

$\mathrm{N}, \mathrm{N}$,diethyldecylamine amine was synthesized according to Scheme 1.

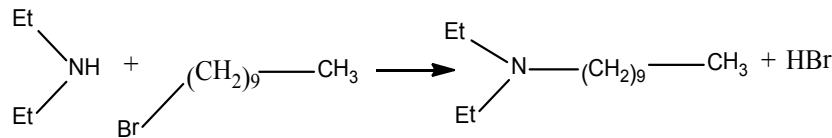

Scheme 1. Synthesis procedure for N,N,diethyldecylamine.

To synthesis the tertiary amine, N,N,diethyl amine $(7.3 \mathrm{~g}, 100 \mathrm{mmol})$ was added to $15 \mathrm{~mL}$ dry acetone which was placed in a clean and predried two-necks flask. 1-bromodecane (11.05 g, $50 \mathrm{mmol}$ 1-bromoodecane) was desolved in $10 \mathrm{~mL}$ dry acetone and was added drop wise to the stirring mixture, which was brought to reflux for 3 h. Upon cooling a white solid precipitated from solution as secondary amine salt. After filtration and separation of the precipitated amine salts tertiary amine was separated from the solution.

\subsubsection{Synthesis of Ammonium Salts}

The synthetic procedure for the target surfactants are shown in Scheme 2. Sample codes and abbreviations used to describe the gemini cationic surfactants are given in Table 1

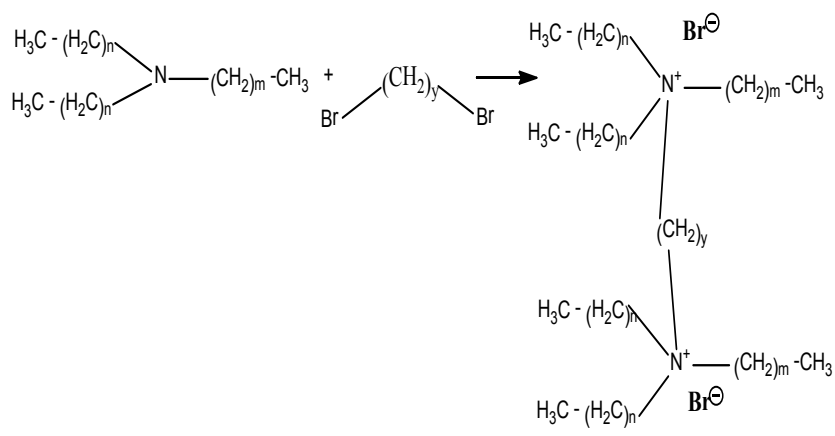

Scheme 2. Synthesis procedure for gemini cationic surfactants solution.

Table 1. Abbreviations used to describe the structure of gemini cationic surfactants

\begin{tabular}{ccccllc}
\hline $\mathbf{n}$ & $\mathbf{m}$ & $\mathbf{y}$ & sample & appearance & solvent & $\begin{array}{c}\text { Yield } \\
(\%)\end{array}$ \\
\hline 1 & 1 & 6 & $2-6-2$ & White solid & Dry acetone & 85 \\
1 & 1 & 10 & $2-10-2$ & White solid & Dry acetone & 86 \\
3 & 3 & 6 & $4-6-4$ & Viscous syrup & Dry acetone & 64 \\
3 & 3 & 10 & $4-10-4$ & Viscous syrup & Dry acetone & 69 \\
1 & 9 & 6 & $10-6-10$ & Viscous syrup & Dry acetone & 70 \\
\hline
\end{tabular}

To synthesis the gemini cationic surfactants, 2-6-2, 4-6-4 and 10-6-10 the corresponding amines (13.12 g, along with $120 \mathrm{mmol} \mathrm{N}, \mathrm{N}, \mathrm{N}$,triethylamine,22.2 g, 120 mmol N,N,N,tributylamine) were added to $15 \mathrm{~mL}$ of dry acetone in a clean and predried two-necks flask. 1, 6-dibromohexan (12.2 g, $50 \mathrm{mmol}$ ) was dissolved in dry acetone and added drop wise to the mixture under stirring. This mixture was refluxed for $48 \mathrm{~h}$. To synthesis the gemini cationic surfactants, $2-10-2$ and $4-10-4$, the corresponding amines $(12.2 \mathrm{~g}$, along with $120 \mathrm{mmo}$ $\mathrm{N}, \mathrm{N}, \mathrm{N}$, triethylamine, and $22.2 \mathrm{~g}, 120 \mathrm{mmolN}, \mathrm{N}, \mathrm{N}$, tributyl 
amine) were added to dry acetone $(15 \mathrm{~mL})$ in a clean and predried two-necks flask. 1,10-dibromodecan (15 g, 50 mmol) was dissolved in dry acetone and was added drop wise to the mixture under stirring. This mixture was refluxed for $48 \mathrm{~h}$. In case of 2-6-2 and 2-10-2 samples upon cooling white solid precipitated from the solution. The solid was filtered and subsequently washed with acetone. The solid material obtained was recrystallized from ethanol and diethyl ether $\left(\mathrm{EtOH} / \mathrm{Et}_{2} \mathrm{O}=1: 9\right)$. In the case of 4-6-4, 4-10-4 and 10-6-10, upon cooling viscous syrup phase was separated from the solution. The viscous syrup then washed with diethyl ether.

For synthesizing the conventional cationic surfactants (12.12 g, $120 \mathrm{mmol}) \mathrm{N}, \mathrm{N}, \mathrm{N}$, triethylamine was added to $15 \mathrm{~mL}$ dry acetone in a clean and predried two-necks flask. 1-bromohexane ( $8.25 \mathrm{~g}, 50 \mathrm{mmol})$ was dissolved in dry acetone and added drop wise to the mixture under stirring. This mixture was refluxed for $48 \mathrm{~h}$. After cooling a white solid precipitated from The solution. The solid material obtained was filtered and washed with acetone. The solid was recrystallized from ethanol and diethyl ether.

\subsection{Organic Modification of Montmorillonite}

A number of modified MMT samples were synthesized by ion-exchange reaction between MMT- $\mathrm{Na}^{+}$and gemini surfactants. First, $10 \mathrm{~g}$ of $\mathrm{MMT}-\mathrm{Na}^{+}$powder was suspended in $500 \mathrm{~mL}$ of deionized water and the mixture was stirred until powder particles were dispersed completely in water. The stoichiometric amount of gemini surfactants were dissolved separately into $100 \mathrm{~mL}$ of deionized water. The surfactants dissolved in water were slowly added to the suspension. The final mixture was stirred for $24 \mathrm{~h}$ at $60^{\circ} \mathrm{C}$. The resulted organo-montmrillonites were filtered from water and washed with deionized water more than 10 times until no bromide ions were detected in the supernatant solution using an aqueous silver nitrate $\left(\mathrm{AgNO}_{3}, 0.1 \mathrm{M}\right)$ solution. The solvent was evaporaed at room temperature. Then the modified montmorillonite was dried in an oven at a suitable temperature (not more than $75^{\circ} \mathrm{C}$ ).

\subsection{Characterization}

FTIR and ATR spectra of gemini cationic surfactants, untreated montmorillonite and modified montmorillonite were obtained using Nicolet FTIR spectrometer over the spectra range of $4000-400 \mathrm{~cm}^{-1}$ with resolution of $4.0 \mathrm{~cm}^{-1}$. The prepared organoclays and $\mathrm{MMT}-\mathrm{Na}^{+}$ were characterized by XRD-Equinox 3900 X-Ray diffractometer operating at $40 \mathrm{KV}$ and $30 \mathrm{~mA}$ with $\mathrm{Cu} \mathrm{K}_{\alpha}$ radiation. The $2 \theta$ ranged from $2^{\circ}$ to $118^{\circ}$ at the scanning speed of $1 \% \mathrm{~min}$.

\subsection{Adsorption Studies}

To study the influence of surfactant structure, alkyl chain and spacer length, on the adsorption capacity of the modified nanoclay for Dye, adsorption rate experiments were performed at initial concentration of $200 \mathrm{mg} / \mathrm{L}$ and pH 5.

All the adsorption experiments were carried out at $24^{\circ} \mathrm{C}$ with a constant agitation speed of $500 \mathrm{rpm}$. For all batch experiments, dye solutions with predetermined concentrations were prepared. Then the nanoclays were added to dye solutions and the mixtures of dye solutions and adsorbents were stirred by a mechanical stirrer. After a fixed contact time, the samples were removed from the stirrer and centrifuged for $5 \mathrm{~min}$ at $5000 \mathrm{rpm}$ to yield a clear solution. The residual Dye concentration was determined at $\lambda_{\max }=571 \mathrm{~nm}$ using a Carry $100 \mathrm{UV}$-Vis spectrophotometer. The decrease in the dye concentration in the dye bath was taken as the amount of dye adsorbed by nanoclayes. The quantity of the dye adsorbed at time $t$, $\mathrm{q}_{\mathrm{t}}(\mathrm{mg} / \mathrm{g})$, was calculated using the following equation:

$q_{t}=\left(C_{o}-C_{t}\right) V / W$

where $\mathrm{C}_{0}(\mathrm{~g} / \mathrm{L})$ is the initial concentration of dye, $\mathrm{C}_{\mathrm{t}}$ ( $\mathrm{g} / \mathrm{L}$ ) is the concentration of dye at any time $\mathrm{t}, \mathrm{V}(\mathrm{L})$ is the volume of dye solution, and $\mathrm{W}(\mathrm{g})$ is the mass of adsorbent.

\section{Results and Discussions}

\section{1 ${ }^{1} \mathrm{H}-\mathrm{NMR}$ and ${ }^{13} \mathrm{C}-\mathrm{NMR}$ Analysis}

The structures of the target compounds synthesized were characterized by ${ }^{1} \mathrm{H}$ NMR, ${ }^{13} \mathrm{C}-\mathrm{NMR}$ analysis. The characterization results of compounds are listed below:

[2-6-2]: 1H-NMR (400 MHz, $\left.\mathrm{D}_{2} \mathrm{O}\right): \sigma 1.16(\mathrm{t}, 18 \mathrm{H})$, 1.31-1.38 (m, $4 \mathrm{H}), 1.55-1.66(\mathrm{~m}, 4 \mathrm{H}), 3.04-3.11(\mathrm{~m}, 4 \mathrm{H})$, 3.19 (q, 12H) ppm. ${ }^{13} \mathrm{C}-\mathrm{NMR}\left(100.16 \mathrm{MHz}, \mathrm{D}_{2} \mathrm{O}\right): \sigma 6.74$, 20.90, 25.23, 52.52, $56.38 \mathrm{ppm}$. 
[2-10-2]: $1 \mathrm{H}-\mathrm{NMR}\left(400 \mathrm{MHz}, \mathrm{D}_{2} \mathrm{O}\right): \sigma 1.18(\mathrm{t}, 16 \mathrm{H})$, 1.19-1.34 (m, 12H), 1.53-1.64 (m, 4H), 3.03-3.11 (3, 4H), 3.19 (q, 4H) ppm. ${ }^{13} \mathrm{C}-\mathrm{NMR}\left(100.16 \mathrm{MHz}, \mathrm{D}_{2} \mathrm{O}\right): \sigma 6.84$, 20.94, 25.61, 28.19, 28.38, 52.50, $56.72 \mathrm{ppm}$.

[4-10-4]: $1 \mathrm{H}-\mathrm{NMR}\left(300 \mathrm{MHz}, \mathrm{D}_{2} \mathrm{O}\right): \sigma 0.79(\mathrm{t}, 18 \mathrm{H})$, $1.05-1.34(\mathrm{~m}, 24 \mathrm{H}), 1.34-1.71(\mathrm{~m}, 16 \mathrm{H}), 2.91-3.15(\mathrm{~m}$, 16H) ppm. ${ }^{13} \mathrm{C}-\mathrm{NMR}\left(75.46 \mathrm{MHz}, \mathrm{D}_{2} \mathrm{O}\right): \sigma$ 12.92, 19.29, 23.17, 25.20, 28.14, 28.31, 28.4, 52.64, 58.05 ppm.

[10-6-10]: 1H-NMR (400 MHz, $\left.\mathrm{D}_{2} \mathrm{O}\right): \sigma 0.82(\mathrm{t}, 6 \mathrm{H})$, $1.12-1.31(\mathrm{~m}, 28 \mathrm{H}), 1.26-1.35(\mathrm{~m}, 12 \mathrm{H}), 1.35-1.48(\mathrm{~m}$, $4 \mathrm{H}), 1.55-1.74(\mathrm{~m}, 8 \mathrm{H}), 3.07-3.22(\mathrm{~m}, 8 \mathrm{H}), 3.22-3.36(\mathrm{~m}$, $8 \mathrm{H})$ ppm. ${ }^{13} \mathrm{C}-\mathrm{NMR}\left(100.16 \mathrm{MHz}, \mathrm{D}_{2} \mathrm{O}\right): \sigma 7.16,8.73$, $13.97,21.21,21.65,22.68,25.36,26.22,29.10,29.45$, 29.64, 31.99, 47.42, 53.47, $57.20 \mathrm{ppm}$.

[4-6-4]: 1H-NMR (400 MHz, $\left.\mathrm{D}_{2} \mathrm{O}\right): \sigma 0.99(3,18 \mathrm{H})$, 1.25-1.52 (m, $16 \mathrm{H}), 1.51-1.85(\mathrm{~m}, 16 \mathrm{H}), 3.01-3.45(3$, $16 \mathrm{H})$ ppm. ${ }^{13} \mathrm{C}-\mathrm{NMR}\left(75.46 \mathrm{MHz}, \mathrm{D}_{2} \mathrm{O}\right): 12.93,19.17$, 19.29, 23.18, 24.59, 52.65, $58.12 \mathrm{ppm}$.

[Mono]: 1H-NMR (400 MHz, $\left.\mathrm{D}_{2} \mathrm{O}\right): \sigma 1.03(\mathrm{t}, 3 \mathrm{H})$, 1.41 (t, 9H), 1.43-1.58 (m, 6H), 1.75-1.87 (m, 2H), 3.26$3.36(\mathrm{~m}, 2 \mathrm{H}), 3.44(\mathrm{q}, 6 \mathrm{H}) \mathrm{ppm} .{ }^{13} \mathrm{C}-\mathrm{NMR}(100.16 \mathrm{MHz}$, $\left.\mathrm{D}_{2} \mathrm{O}\right): \sigma 7.54,14.07,21.45,22.39,25.83,31.05,52.98$, $56.96 \mathrm{ppm}$.

The chemical structure, ${ }^{1} \mathrm{H}-\mathrm{NMR}$ and ${ }^{13} \mathrm{C}-\mathrm{NMR}$ spectra of 2-6-2 was illustrated in Figure 1(a), 1(b) and $1(\mathrm{c})$.

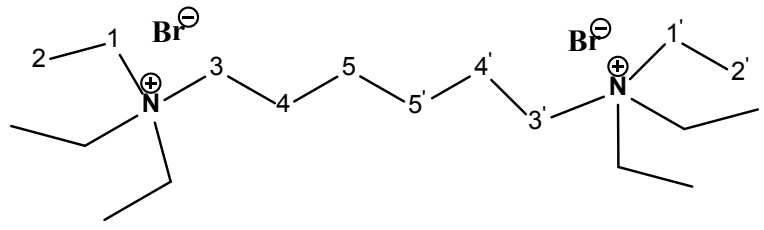

(a)

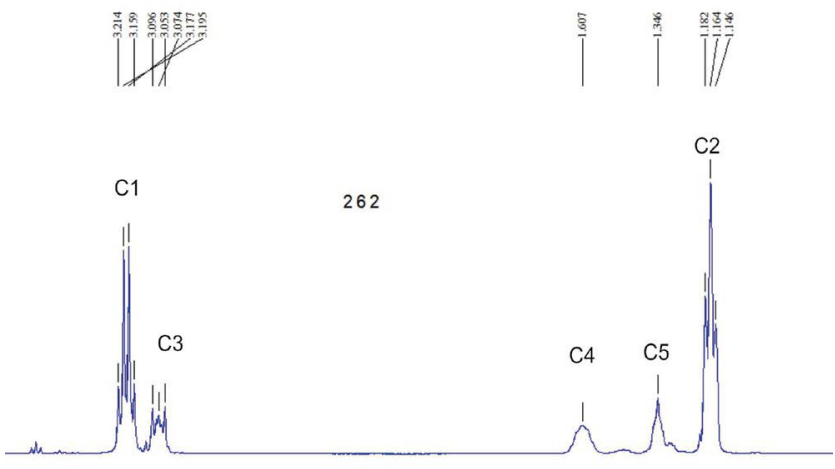

(b)

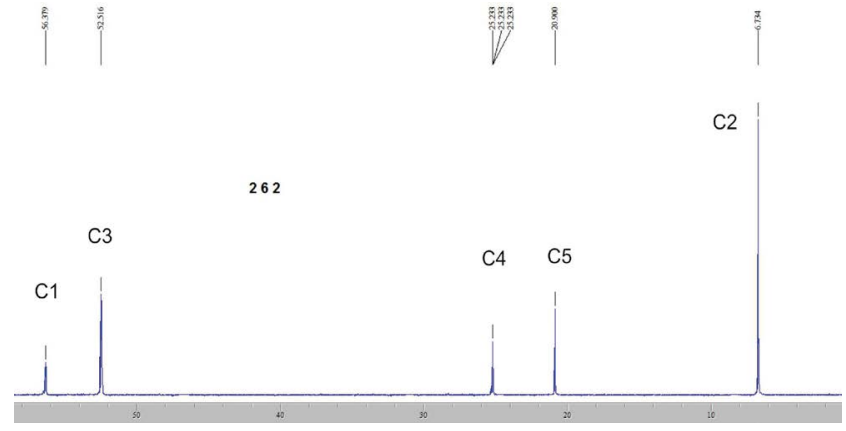

(c)

Figure 1. The chemical structure (a), 1H-NMR (b) and 13C-NMR(c) spectra of 2-6-2.

In the ${ }^{1} \mathrm{H}-\mathrm{NMR}$ spectra, a band was observed at $1.164 \mathrm{ppm}$ which was assigned to $-\mathrm{CH}_{3}$ groups $(\mathrm{C} 2$, $\mathrm{C} 2$ ). The bands at 1.346 and $1.607 \mathrm{ppm}$ were attributed to the structure of $-\mathrm{CH}_{2}$ groups $((\mathrm{C} 5, \mathrm{C} 5)$ and $(\mathrm{C} 4, \mathrm{C} 4)$ respectively). The chemical shifts at 3.074 and $3.195 \mathrm{ppm}$ are due to $-\mathrm{CH}_{2}-\mathrm{N}$ groups $\left(\left(\mathrm{C} 3, \mathrm{C} 3{ }^{\prime}\right)\right.$ and $\left(\mathrm{C} 1, \mathrm{Cl}^{\prime}\right)$ correspondingly).

\subsection{Fourier Transform Infra-Red Spectroscopy Analysis}

The FTIR spectra of surfactants, MMT and modified montmorillonite are shown in Figure 2 and Figure 3 the FTIR spectra in Figure 3 representing the major changes of montmorillonite before and after surfactants modifications with surfactants.

In MMT, The band at $3630 \mathrm{~cm}^{-1}$ was assigned to the hydroxyl $(-\mathrm{OH})$ stretching vibration for the structural hydroxyl group in the interlayer of clay and the broad absorption bands at $3436 \mathrm{~cm}^{-1}$ was ascribed to the stretching vibration of the hydrogen bonded water adsorbed within the interlayer of the clay. The peak at $1630-1650 \mathrm{~cm}^{-1}$ was corresponded to $\mathrm{H}-\mathrm{O}-\mathrm{H}$ bending vibrations. Complex bands at $1050 \mathrm{~cm}^{-1}$ were typical for stretching vibrations of $\mathrm{Si}-\mathrm{O}$ and $\mathrm{Al}-\mathrm{O}$ bonds ${ }^{3}$. The other strong absorption bands at $526 \mathrm{~cm}^{-1}$ and $460 \mathrm{~cm}^{-1}$ indicate the presence of $\mathrm{Al}-\mathrm{O}-\mathrm{Si}$, and $\mathrm{Si}-\mathrm{O}-\mathrm{Si}$ bending vibrations respectively"?

The presence of the alkyl groups in modified montmorillonite shows additional bands compared to MMT. For all modified montmorillonite the presence of two additional peaks at about 2920 and $2850 \mathrm{~cm}^{-1}$ were attributed to asymmetric and symmetric vibrations of $\mathrm{CH}_{2}$ groups from the alkyl chains of gemini surfactants, 
respectively. The bending vibration of the $\mathrm{C}-\mathrm{H}$ bonds of the gemini surfactants occurred at 1465 and $1385 \mathrm{~cm}^{-1}$.

The band intensities at $3436 \mathrm{~cm}^{-1}$ (stretching bond of water adsorbed within the interlayer of the clay) and $1630-1650 \mathrm{~cm}^{-1}$ (bending vibrations of MMT water) diminished after modification with surfactants. In particular, the peak at $3400 \mathrm{~cm}^{-1}$ almost vanished. This may be due to the formation of electrostatic interactions between the quaternary ammonium groups of gemini surfactant and $-\mathrm{OH}$ groups of modified MMT and this increase in hydrophobicity changes the structural from hydrophilic to hydrophobic behaviour

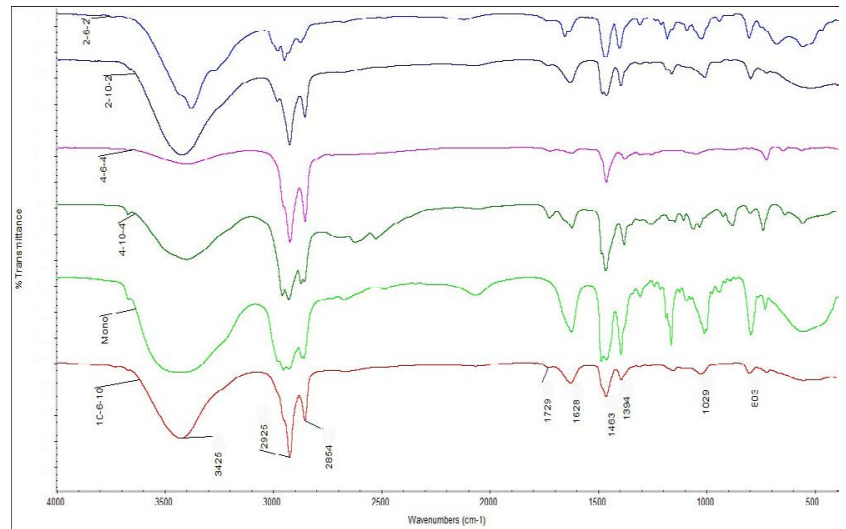

Figure 2. FT-IR spectra of the cationic surfactants.



Figure 3. FT-IR spectra of the sodium montmorillonite (MMT) and modified montmorillonite.

ATR was used to explain the molecular conformation of the intercalated surfactant chains attached on MMT and provide a better insight to the interlayer structure ${ }^{35}$. The frequency and width of stretching $-\mathrm{CH}_{2}$ bands are sensitive to the gauche/trans conformation ratio and the packing density of surfactant ${ }^{2}$. In the ATR spectra of modified montmorillonite shown in Figure 4 (except Mono and 2-6-2), asymmetric and symmetric vibrations of $-\mathrm{CH}_{2}$ groups from the alkyl chains of the gemini surfactants (2920 and $2850 \mathrm{~cm}^{-1}$ ) were observed. This means that all the surfactants have intercalated insight to the interlayer structure.

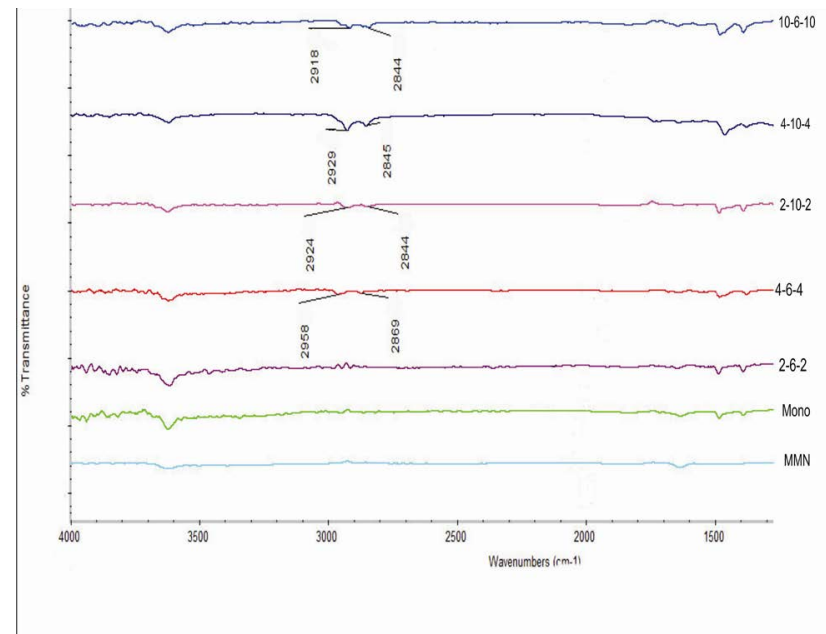

Figure 4. ATR infrared spectrum of $\mathrm{CH} 2$ stretching band for the sodium montmorillonite (MMT) and modified montmorillonite.

\subsection{XRD Analysis}

Figure 5 presents The XRD patterns of MMT, modified montmorillonite and Nanofil3010. Their d-spacing data were calculated by Bragg equation: $2 \mathrm{~d} \sin \theta=\mathrm{n} \lambda$ (Table 2 ).

Table 2. d-spacing data of clay samples

\begin{tabular}{lcc}
\hline Sample & $\mathbf{2 \theta}$ & d space $\left(\mathrm{A}^{\circ}\right)$ \\
\hline MMT & 7.98 & 11.08 \\
Nanofill3010 & 7.65 & 11.56 \\
Mono & 6.5 & 13.6 \\
262 & 6.28 & 14.08 \\
2102 & 6.31 & 13.99 \\
464 & 6.09 & 14.51 \\
4104 & 4.96 & 17.82 \\
10610 & 4.67 & 19.01 \\
\hline
\end{tabular}


As shown in Figure 5, a diffraction peak around $2 \theta$ $=7.98^{\circ}$ is showed by Na-MMT, equaling a basal spacing of $11.08 \mathrm{~A}^{\circ}$ for the layered silicates in montmorillonite. This value consistent with the $d_{001}$ spacing of natural MMT as reported by supplier $\left(11.7 \mathrm{~A}^{\circ}\right)$. The diffraction peaks at $2 \theta$ $=6.5^{\circ}, 6.28^{\circ}, 6.31^{\circ}, 6.09^{\circ}, 4.96^{\circ}$ and $4.67^{\circ}$ with corresponding basal spacing of 13.6, 14.08, 13.99, 14.51, 17.82 and 19.01 were displayed in the samples of Mono, 2-6-2, 2-10-2, 4-6-4, 4-10-4 and 10-6-10, respectively and the shifting of peaks from 7.98 to 4.67 resulted from the expansion of basal spacing of silicate layers by modification. These results show the inercalation of silicates layers by cationic Gemini surfactants has occurred and the layer distance has increased but the ability of modifying substance to penetrate into the interlayer space based on $d_{001}$ values is different. For the Nanofil3010 sample, a diffraction peak at $2 \theta=7.65^{\circ}$ equaling a basal spacing of $11.56 \mathrm{~A}^{\circ}$ was observed, indicating that the layers spacing of the silicates layers had a little change compared with Na-MMT. However, all the modified montmorillonite with cationic Gemini surfactants compare to Nanofil3010 sample show the bigger $\mathrm{d}$ spacing, which was ascribed to the big ratio of intercalation. On the other hand, Table 3 depicts the correlation between the layer spacing of modified montmorillonite with cationic Gemini surfactants with the spacer length and chains length of gemini surfactant. With increasing the spacer length and chains length of gemini surfactant, the basal spacing of modified montmorillonite increase obviously. The calculated values of $14.08,13.99,14.51 \mathrm{~A}^{\circ}$ for $2-6-2,2-10-2$ and 4-6-4 samples were consistent with a lateral-monolayer arrangement of the cationic Gemini surfactants in the interlayer space and the value of $17.82 \mathrm{~A}^{\circ}$ for $4-10-4$ is corresponding to a lateral bilayer ${ }^{\beta}$, Pseudotrilayer arrangement may well explain the basal reflection at 19.8 $\mathrm{A}^{\circ}$ and the $\mathrm{d}$-spacing value of 19.01 in the 10-6-10 sample, suggesting the transitional structure between the bilayer and pseudotrilayer ${ }^{30,36}$. Finally results show that gemini surfactant organoclays have better intercalation than conventional ones and in gemini surfactant, 4-10-4 and 10-6-10 were more efficient than other gemini surfactant in intercalation.

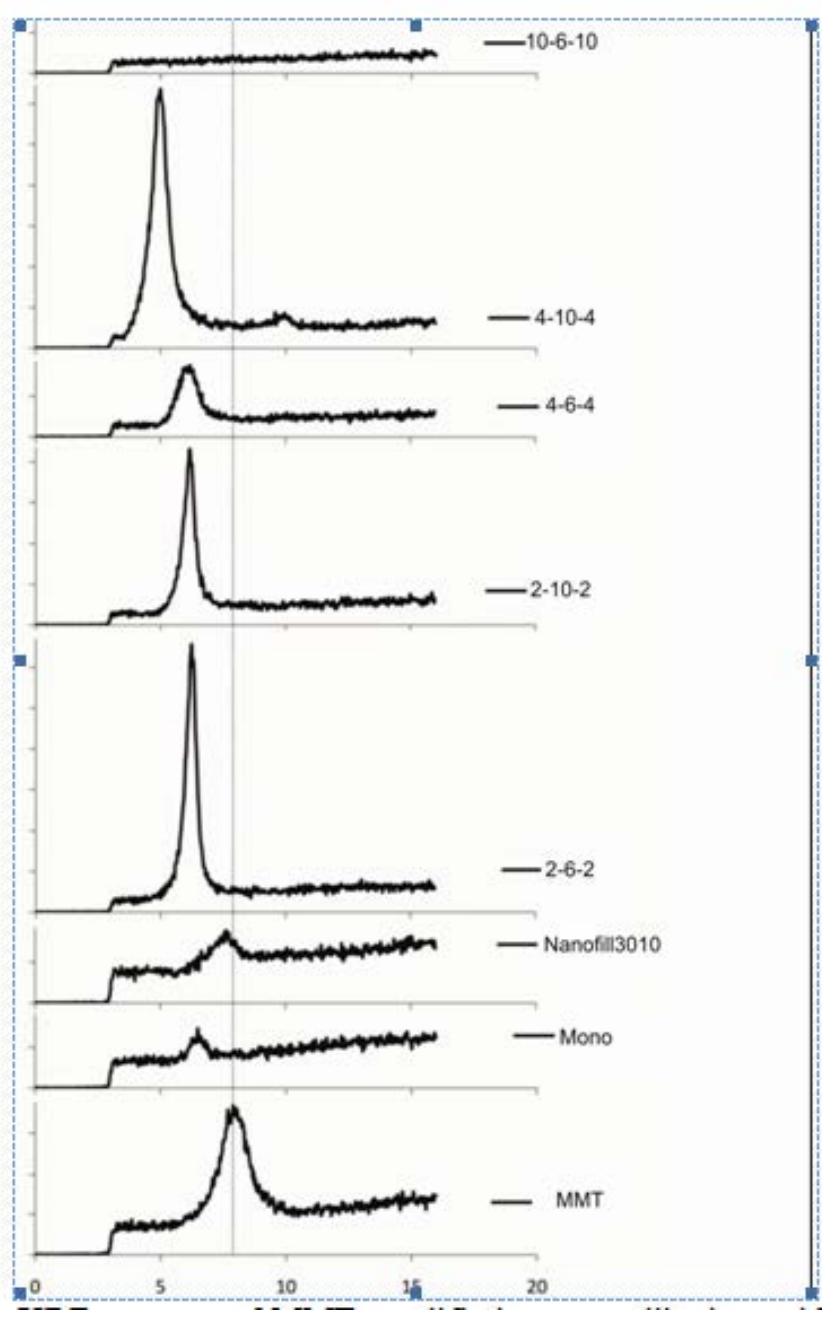

Figure 5. The XRD patterns of MMT, modified montmorillonite and Nanofill 3010.

\subsection{Adsorption Experiment}

In order to investigate the effect of modification on dye removal of modified nanoclay, a series of modified nanoclay (Mono, 2-6-2, 2-10-2 and 4-6-4) were chosen for dye adsorption experiments. The adsorption of dye by samples as a function of contact time is represented in Figure 6. 


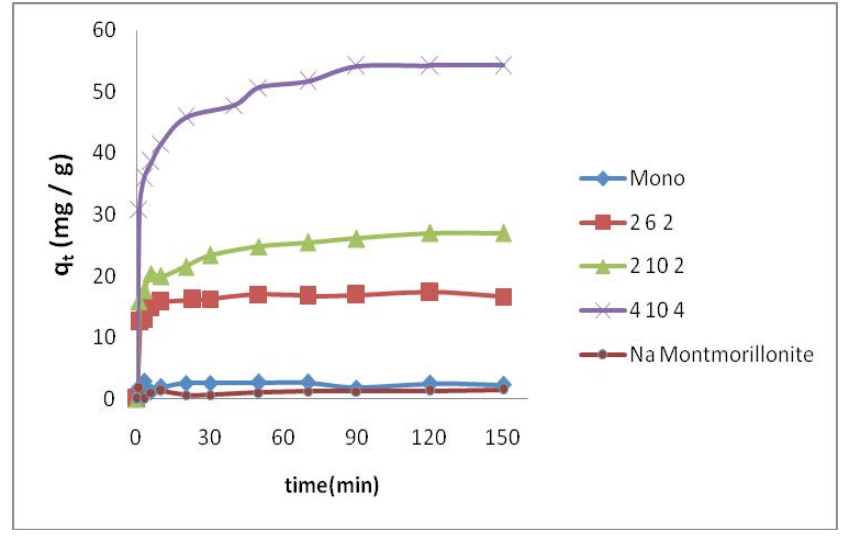

Figure 6. Amount of dye adsorbed onto MMT and modified montmorillonite as a function of contact time ( $\mathrm{min})$.

This figure indicates that by surface modification and placing of surfactants into interlayer spaces in the clay, the adsorption capacity of dye improves. Furthermore MMT$\mathrm{Na}^{+}$modified by gemini surfactant $(2-6-2,2-10-2,4-6-$ 4) demonstrated higher adsorption capacity compared to the montmorillonite modified with conventional one (Mono). In the case of MMTs modified with cationic gemini surfactants, with increasing alkyl chain and spacer length of gemini surfactants the adsorption capacity of the organo- montmorillonites increases, and the 4-10-4 sample with the largest interlayer distance has the higher adsorption capacity. It seems that, the differences could be related to the molecular structures of the employed surfactant. This can be attributed to the fact that with increasing the spacer length and the length of the chain of the synthesized gemini surfactants, the distance between the layers of the modified montmorillonite increases and adsorption capacity increases because of higher surface area achieved (Table 2). The XRD reflections show that the Mono sample has a lower $d_{001}$ value than geminies (2-6-2, 2-10-2, 4-6-4) and they have better intercalation than the conventional ones, suggesting that modification with conventional surfactant did not increase the distance between the MMT-Na+ layers.

Furthermore, high adsorption of dye on modified nanoclay with gemini surfactant compare to mono sample was attributed to electrostatic interaction between the positively adsorption site of the adsorbent and the negatively charged dye. Negatively charged surface of nanoclay may adsorb the cationic surfactants by two steps. First via an ion exchange mechanism, a layer of cationic surfactants on the surface of clay is formed. One of the positive ends of the cationic surfactants are exchanged with the interlayer exchangeable cations of the clay $\left(\mathrm{Na}^{+}\right)$ and the other head of the cationic surfactants is arranged outward. Therefore, after modification, the surface of nanoclay has quaternary ammonium groups which can increase the electrostatic interaction between the anionic groups of dye and the cationic groups of adsorbent.

Second through hydrophobic-hydrophobic interactions, cationic surfactant alkyl chains are attached to hydrophobic structure of dye $e^{\beta}$. In this adsorption, mechanism of this adsorption process can be explained according to adsorption/partition model. According to this model, the organic fraction of clay modified by surfactant with long chains behaves as a partition medium and clay act as the conventional adsorbent in the uptake of organic compounds In our study, adsorption of dye on modified clay may take place by the interaction of the dye with organic fraction (as a partition medium) of the modified nanoclay. With increasing the spacer length and chain length of the synthesized gemini surfactants, adsorption of dye by corresponding modified nanoclay increases and the and the Van der Waals forces and hydrophobic interaction can contribute between dye and organoclay and partition of the dyes into hydrophobic regions plays an important role in dye uptake

\section{Conclusions}

In this paper, series of gemini surfactants with different alkyl spacer and alkyl chain were synthesized. Based on FTIR, HNMR and ${ }^{13} \mathrm{CNMR}$ results, gemini surfactants have been synthesized efficiently with high purity. surfactant, 2-6-2, 2-10-2, 4-6-4, 4-10-4, 10-6-10 and conventional cationic surfactant were used to modify the surface of sodium montmorillonite. The results obtained from FTIR and ATR show that these surfactants were successfully chemically bonded on the clay. Presence of the bands at $2920 \mathrm{Cm}^{-1}$ and $2850 \mathrm{Cm}^{-1}$ which are due to asymmetric and symmetric vibration of $-\mathrm{CH}_{2}$ groups from the alkyl chain of the gemini surfactant and the bands at $1385 \mathrm{Cm}^{-1}$ and $1463 \mathrm{Cm}^{-1}$ due to bending vibration of $\mathrm{C}-\mathrm{H}$ bond of the gemini surfactant show the presence of these surfactants on the nanoclay Gradual diminishing the band at $3400 \mathrm{~cm}^{-1}$ is also another proof for the modification of the clay by the surfactants. The XRD patterns indicate that the layered silicates have been 
intercalated by these Gemini surfactants. With increasing the spacer length and chain length at the synthesized gemini surfactants, the basal spacing of the modified montmorillonite increases. With increasing in length of gemini surfactant one can go from a monolayer to pseudotrilayer arrangement.

Results indicate that by surface modification the adsorption capacity of dye improves. Na montmorillonite modified by gemini surfactant shows higher adsorption capacity compared to the montmorillonite modified with conventional one (mono) and as alkyl chain and spacer length of gemini surfactants increase, the adsorption capacity of the organo-MMTs improves, and the 4-10-4 sample with the largest interlayer distance has the higher adsorption capacity.

\section{References}

1. Yang S, Gao M, Luo Z. Adsorption of 2-Naphthol on the organomontmorillonites modified by Gemini surfactants with different spacers. Chemical Engineering Journal. 2014; 256:39-50.

2. Liua B, Wang X, Yangb B, Sun R. Rapid modification of montmorillonite with novel cationic Gemini surfactants and its adsorption for methyl organge. Materials Chemistry and Physics. 2011; 130(3):1220-1226.

3. Murray HH. Applied Clay Mineralogy. Elsevier; 2007. Chapter 2. p. 5-32.

4. Wilson MJ. Clay Minerology.London: Chapman and Hall; 1995. Chapter 4. p.300-26.

5. Wilson MJ. A Hand Book of Determinative Methods in Clay Mineralogy. Glasgow and London: Chapman and Hall; 1987. Chapter 1. p. 1-23.

6. Newman ACD. Chemistry of Clays and Clay Minerals. England: Longman Scientific and Technical; 1987. Chapter2. p. 12-116.

7. Daoudi M, Boughaleb Y, El Gaini L, Meghea I, Bakasse M. Modeling of alkyl quaternary ammonium cations intercalated into montmorillonite lattice.Materials Research Bulletin. 2013; 48(5):1824-1829.

8. Sanqin W, Zepeng Z, Yunhua W, Libing L, Jiansheng Z. Influence of montmorillonites exchange capacity on the basal spacing of cation-anion organo montmorillonites. Materials Research Bulletin.. 2014; 59:59-64.

9. Ren X, Zhang Z, Luoa H, Huc B, Dang Z, Yanga C, Li L. Adsorption of arsenic on modified montmorillonite.Applied Clay Science. 2014; 97-98:17-23.

10. Fatimah I, Huda T. Preparation of cetytrimethylammonium intercalated Indonesian montmorillonite for adsorpiton of toluene.Applied Clay Science. 2013; 74:115-120.

11. Kozak M, Domka L. Adsorption of the quatemary ammonium salts on montmorillonite. Journal of Physics and Chemistry of Solids. 2004; 65:441-445.
12. Huang G, Gao J, Wang X.Preparation and characterization of montmorillonite modified by phosphorus-nitrogen containing quaternary ammonium salts. Applied Surface Science. 2012; 258(8):4054-4062.

13. Wang C, Jiang X, Zhou L, Xi G, Chen Z, Duan M, Jiang X. Chemical Engineering Journal. 2013; 219:469-477.

14. Liu P. Polymer modified clay minerals: A review.Applied Clay Science. 2007; 38:64-76.

15. Kim N H, Malhotra S V, Xanthos M. Modification of cationic nanoclays with ionic liquids.Microporous Mesoporous Mater. 2006; 96(1-3):29-35.

16. Livi S, Duchet-Rumeau J, Gerard J. Supercritical CO2 ionic liquid mixtures for modification of organoclays. Journal of Colloid and Interface Science. 2011; 353(1):225-230.

17. Huang G, Gao J, Wang X. Appl. Surf. Sci. 2012; 258:40544062.

18. Go" k O, O" zcan AS, O" zcan A.Adsorption behavior of a textile dye of Reactive Blue 19 from aqueous solutions onto modified bentonite. Applied Surface Science. 2010; 256(17):5439-43.

19. Kozak M, Domka L. J. Phys. Chem. Solids. 2004; 65:441445.

20. Zhang Z, Liao L, Xio Z.Utltrasound-assisted preparation and characterization of anionic surfactant modified montmorillonites. Appl. Clay Sci. 2010; 50:576-81.

21. Heinz H, Vaia RA, Krishnamoorti R, Farmer BL.Self-Assembly of Alkylammonium Chains on Montmorillonite:Effect of Chain Length, Head Group Structure, and Cation Exchange Capacity. Chemistry of Materials. 2007; 19(1):59-68.

22. Menger F M, Littau CA. Gemini surfactants: a new class of self-assesmbling modelcules. Journal of AmeicanChemical Society. 1993; 115 (22):10083-90.

23. Sekhon BS. Gemini(dimeric) Surfactants - The Two-Faced Molecules.Resonance. 2004; 9(3):42-9.

24. Obł E, Piecucha A, Krasowsk A, Łuczy'nsk J.Antifungal activity of gemini auaternary ammonium salts. Microbiological Research. 2013; 168(10):630-8.

25. Xu XJ, Guo J W, Zhong X. Synthesis and properties of novel cationic gemini surfactants with adamantane spacer. Chinese Chemical Letters. 2014; 25:367-9.

26. Zana R. Dimeric and oligomeric surfactants. Behavior at interfaces and in aqueous solution: a review. Advances in Colloid and Interface Sci. 2002; 97(1-3):205-53.

27. Gharanjig K, Arami K, Bahrami H, Movassagh B, Mahmoodi NM. Synthesis, spectral properties and application of novel manoazo disperse dyes derived from N-ester-1,8-napthalimide to polyester. Dyes and Pigments. 2008; 76(3):684-9.

28. Tehrani-Bagha AR, Bahrami H, Movassagh B, Arami M, Menger FM. Interactions of gemini cationic sufactants with anionic azo dyes and their inhibited effects on dyeability of cotton fabric. Dyes and Pigments. 2007; 72(3):331-8.

29. Tehrani-Bagha AR, Bahrami H, Movassagh B, Arami M, Amirshahi SH. Menger FM. Dynamic adsorption of gemini and conventional cationic surfactants onto polyacryloni- 
trile. Colloids and Surfaces. A: Physicochemical and Engineering Aspects. 2007; 307(1-3):121-7A.

30. Qi L, Liao W, Bi Z. Adsorption of conventional and gemini cationic surfactants in nonswelling and swelling layer silicate. Colloids and Surfaces. A: Physicochemical and Engineering Aspects 2007; 302(1-3):568-72.

31. Zhong X, Guo J, Feng L, Xu X, Zhu D. Cationic Gemini sufactants based on adamantane:Synthesis, surface activity and aggregation properties. Colloids and Surfaces. A: Physicochemical and Engineering Aspects. 2014; 441:572-80.

32. Zana R, Benrraou M, Rueff R. Alkanediyl-alpha., omega.-bis(dmethylalkylammonium bromide) surfactants.1.Effect of the spacer chain length on the critical micelle concentration and micelle ionization degree. Langmuir. 1991; 7(6):1072-75.

33. Jincheng W, Xiaoyu Z, Wenli H, Nan X, Xingchen P.Synthesis of hyper-branched quaternary ammonium salt and its application into montmorillonite. Powder Technology. 2012; 221:80-9.

34. Qian X, Liao M, Zhang W.Surface modification of mont- morillonite and application to the preparation of polybutadiene/montmorillonite nanocomposites. Polymer International. 2007; 56(3):399-408.

35. Vaia RA, Teukolsky RK, Giannelis EP. Interlayer Structure and Moelcular Environment of Alkylammonium Layered Silicates. Chemistry of Materials. 1994; 6(7):1017-22.

36. Jianxi Z, Hongping H, Jiugao G, Dan Y, Xiande X.Arrangement models of alkylammonium cations in the interlayer of HDTMA pillared montmorillonites. Science Bulletin. 2003; 48(4):368-72.

37. Foroughi M, Abolghasemi H, Esmaielia M, Nazari Gh, Rasem B.Experimental study on the adsorptive behavior of Congo red in cationic surfactant-modified tea waste. Process Safety Environmental Protection. 2015; 95:226-36.

38. Anirudhan TS, Ramachandran M. Adsorptive removal of basic dyes from aqueous solutions by surfactant modified bentonite clay(organoclay): Kinetic and competitive adsorption isotherm. Process Safety Environmental Protection. 2015; 95:215-25. 